\title{
Corporate Governance And Mindfulness: The Impact Of Management Accounting Systems Change
}

John J. Williams, Singapore Management University, Singapore Alfred E. Seaman, Kemerer Group Inc., Canada

\begin{abstract}
The International Federation of Accountants (2009) argues that a governance structure should go beyond conformance with regulations and equally support a performance dimension that can lead to better outcomes. This paper explores the relationship between these two governance dimensions and the capacity for mindfulness, utilizing organizational theory that describes high reliability organizations. Survey data was obtained from top-level accounting professionals in a sample of 124 Canadian firms. Regression results support the hypothesis that both the conformance and performance dimensions of governance are significant determinants of the capacity for mindfulness. Additional analysis shows that the explanatory power of this relationship persists when management accounting systems change is low but it is significantly greater under conditions of high management accounting systems change. The latter finding is notable in that the most important determinants of the capacity for mindfulness emerge from the performance dimension and not the conformance dimension, which has implications for achieving a balanced governance structure.
\end{abstract}

\section{INTRODUCTION}

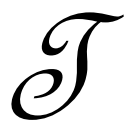

he study of corporate governance in academia is diverse and complex, spanning literatures across accounting, finance, law, economics and management. Mainstream accounting research predominantly focuses on the relationship between structural attributes of governance, such as board characteristics, ownership qualities, anti-takeover variables, and executive compensation (Shleifer and Vishny, 1997; Bushman and Smith, 2001; Xie, Davidson III and Dadalt, 2003; Larcker, Richardson and Tuna, 2007) and financial reporting outcomes including abnormal accruals as a surrogate for earnings quality (Dechow, Sloan and Sweeney, 1995; Klein, 2002), earnings restatements or fraud (Beasley, 1996; Dechow et al., 1996; Erickson, Hanlon and Maydew, 2006), and future operating performance (Gompers, Ishii and Metrick, 2003; Core, Guay and Rusticus, 2006). The role of the accountant in business is not addressed in this framework.

Apart from generic survey data, much of the practice literature on governance emanates from accounting institutions globally and is prescriptive in nature. It tends to feature generally accepted routines overarching corporate governance, supported by key principles of action, international guidance on good practice, and is directed at and emphasizes the role of the professional accountant in business (e.g., International Federation of Accountants, 2008, 2009; PricewaterhouseCoopers, 2008). The justification supporting this agenda is that successful organizations engage in routines that adhere to governance principles; periodically assess the effectiveness of their governance systems; pursue ideal benchmarks; and, adapt to environmental change by improving their action repertoire of processes and procedures. One assumption overarching virtually all this literature is that increasing or altering governance standards to match "best practices" can produce more effective outcomes and higher stakeholder value across all entities (International Federation of Accountants, 2008).

These directives are remarkably similar to the adaptive organizational forms for complex, turbulent environments that are discussed in the literature on high reliability organizations (HROs), except that the practice 
accounting literature suppresses or ignores the role of cognitive processes that constitute mindfulness which, in turn, is instrumental in producing reliable or effective outcomes (Hannan and Freeman, 1984; Woods, 1988; Weick and Sutcliffe, 2001; Weick, Sutcliffe and Obstfeld, (1999). This paper reports the results of an exploratory empirical study that examines the relationship between two major dimensions of governance presented in the professional literature (International Federation of Accountants, 2009) and the concept of mindfulness at the level of the individual accountant in the firm. In addition, the impact of management accounting systems change (MASC) on this relationship is considered, given its pivotal informational role in all organization structural design (Galbraith, 1977; Hopwood, 1987; Otley; 1999) and its distinctive presence in any governance system.

The remainder of the paper is structured in the following manner. The subsequent section briefly reviews the prescriptive professional literature on corporate governance, develops the linkage of governance to cognitive processes of mindfulness, and considers the role of management accounting systems (MAS) change ${ }^{1}$ in this relationship. Next, a methods section details the sample, measurement of variables, and analytic framework, followed by a results section and a discussion section. Some implications, limitations and suggestions for further research close out the final section.

\section{LITERATURE REVIEW AND HYPOTHESES DEVELOPMENT}

\section{Governance}

Among the many governance frameworks offered in the practice literature, the IFAC's (2009) depiction is exemplary and representative in terms of fundamental procedures and principles. It presents a governance framework composed of two dimensions: the conformance dimension, favouring a more historic view; and the performance dimension, which is more forward-looking in perspective. Conformance pertains to responsibilities primarily dealing with accountability, assurance, and risk oversight. Six types of routines in particular are mentioned: (1) assessing the entire value chain of risk analysis, including strategic, tactical and operational risk; (2) maintaining effective functioning to achieve strategic and operational goals; (3) developing information systems that are accurate and reliable; (4) providing reliable stewardship; (5) detecting and preventing criminal activities; and (6) fostering compliance with all regulations (IFAC, 2009, pp. 8-9). The performance dimension centres on routines pertaining to strategy, value creation, and resource utilization. Specifically, these include (1) creating a robust decision-making process, determining risk appetite, and evaluating successful performance; (2) matching operations and resources to strategy for a given level of risk appetite; and (3) determining when and where an organization's action repertoire needs to fluctuate in response to a changing internal or external environment (IFAC, 2009, p. 9).

Overarching the standardized routines that constitute the conformance and performance dimensions are 12 principles developed from case studies presented in "Enterprise Governance: Getting the Balance Right" (IFAC, 2004). This report dealt with governance failures and what must be done to ensure that things go right. Seemingly, there is a desire to instil reliability in any governance structure. The IFAC describes how this should happen: "Successful organizations adhere to governance principles, and periodically evaluate results to ensure continuing effectiveness of their governance systems. ... governance procedures and practices should be benchmarked against those of successful organizations ... As organizations and their environments change, the governance system must adapt to future opportunities and threats by improving processes and practices" [emphasis added] (IFAC, 2009, p.5). The implication is that increased levels of governance applied consistently will increase the chances of success and reduce the probability of failures, thus leading to stable performance outcomes. Moreover, assessments of this "benchmarked" repertoire of standardized routines will be variable (performed periodically), presumably brought about by cognitive processes that underpin awareness in the professional accountant, although this mechanism is not addressed. Thus, stability is assigned to governance routines for given contexts while variation underpins assessments of the system under the IFAC framework.

\section{Linkage between Governance Routines and Cognitive Processes}

HROs, such as aircraft carriers and nuclear power plants, also embody processes and systems to suppress failures in their quest for unwavering effectiveness, or high reliability, but they reverse the pattern of processes mentioned above: "... there is variation in activity, but there is stability in cognitive processes." (Weick et al., 1999, 
p. 87). What happens essentially is that in an uncertain, unpredictable environment, there is a continuous mutual adjustment that takes place each time a routine is re-enacted because it does not unfold exactly the same way as it did previously (Feldman, 1989; March and Olsen, 1989; Weick et al., 1999). Therefore, any set of standardized procedures is enacted in a variable manner in the face of uncertainty since routines cannot deal with what was not planned. Routines must become variable or action would grind to a halt. Landau and Chisholm (1995), for instance, argue that potential information about threats, capability and the environment are harnessed precisely because of this adaptive re-alignment of routines. But this new knowledge is foregone unless there is "... continuous mindful awareness of these variations." (Weick et al., 1999, p. 88).

In elaborating on how this cognition operates, Weick et al. (1999) cite the view of Woods (1988, p. 132): "To be opportunistic and flexible in order to detect and to adapt to events which require revision of situation assessment and plans ... problem solvers need to revise their understanding of the situation, their evidence collection and evaluation tactics, or their response strategy when new events are detected and evaluated." However, when things go wrong or, put differently, unexpected events occur, then evaluations and strategies need to change but these revisions are only possible because cognitive processes of understanding, monitoring, and revising do not vary. As Weick et al. $(1999$, p. 87$)$ point out "These stable cognitive processes do the 'detecting', the variable patterns of activity do the 'adapting' to events which require revision."

\section{Components of Mindfulness}

The capability to discover and manage unexpected events is referred to as "mindfulness" in the HRO literature (Langer, 1989, 1997; Rochlin, 1989; Weick et al, 1999; Weick and Sutcliffe, 2001). Mindfulness works because of the counterintuitive response to early stages of trouble; instead of complacency and exploitation of existing performance routines (Miller, 1993), there is a strong response to weak signals of trouble and danger. Hence, cognitive processes that focus on failures, simplifications, operations, resiliencies, and expertise, facilitate mindful updating. Weick and Sutcliffe (2001, p. 53) characterize the first three processes as "mindful anticipation of the unexpected" whereas the latter two are treated as "mindful containment of the unexpected." The idea is that when these processes are viewed collectively in an organization they jointly induce "a rich awareness of discriminatory detail and a capacity for action." (Weick et al., 1999, p. 88). These processes, then, appear to coincide perfectly with the challenges, requirements and action capability demanded of professional accountants (IFAC, 2009) which are augmented by more compliance and performance routines.

\section{Mindful Anticipation}

Successful HROs have a preoccupation with failure simply because serious failures are rare occurrences which therefore limit the capacity to learn. To compensate, HROs encourage and reward the reporting of all errors (Rochlin, 1993), treat near misses as threats and not safety (March, Sproull, and Tamuz, 1991), and develop proxies for failure that are a consequence of success, such as reduced attention, complacency, inertia, risk aversion, or constrained search (Sitkin, 1992).

A second characteristic of mindful anticipation is the reluctance to simplify interpretations which could otherwise produce blind spots, limit interactions, or homogenize expectations. Instead, HROs increase the number of precautions enacted (Roth, 1997), they make fewer assumptions and socialize their people to notice more (Xiao, Milgram, and Doyle, 1997) and, importantly, they attempt to cultivate requisite variety by matching internal with external complexities (Perrin, 1995). These behaviours are accomplished through myriad committees and meetings, frequent job rotation, retraining, and acquiring new employees with diverse backgrounds. There is the additional thinking in HROs that interpersonal skills, respect yet scepticism in interaction, and wariness in others' competence, are instrumental in detecting anomalies and arresting failure (Weick and Sutcliffe, 2001).

The third element of mindful anticipation is sensitivity to operations. HROs try to reverse the traditional authority structure by creating dense interaction among different levels of the organization to create an integrated picture of operations in the moment (Weick et al., 1999), or what Roberts and Rousseau (1989) call "having the bubble". If one individual can have the bubble at any moment, then the chance that any one error becomes linked with another to interact in ways not seen before will be reduced. In turn, this allows continuous adjustments which 
prevent small errors from accumulating (Weick, 1990). However, contemporary management practices that downsize and add production pressures thwart sensitivity to operations because there are fewer people to do more routines. Not only is there less slack and more rigidity or tunnel vision but, as well, people revert to previous overlearned behavior and overlook or miss latent problems. So, HROs focus continuously on operations through face-toface communication, bypass the conventional hierarchy and move problems toward expertise, and maintain the big picture through sharing real time information (Roberts, Stout, and Halpern, 1994).

\section{Mindful Containment}

Resilience and underspecification of structures are two major mechanisms that constitute mindful containment. Wildavsky (1991, p. 77) suggests that anticipation refers to the "prediction and prevention of potential dangers before damage is done" while resilience refers to the "capacity to cope with unanticipated dangers after they have become manifest, learning to bounce back". Weick et al. (1999) stress that resilience is not just about moving on from the discovery of errors but, also, it is the capacity to cope with surprises in the moment.

Informal networks of diverse people and expertise are able to come together with great speed and provide rapid negative feedback when events emerge that were impossible to anticipate, and then disappear just as quickly. As Weick (1990) makes clear, these individuals manifest bricolage and the ability to recombine past experience to deal with "never seen before" surprises. This behaviour happens because hierarchical structures and decision structures are blended together, unlike traditional authority structures. Essentially, then, experience and expertise are more important than rank. Solutions are brought together quickly, mostly due to extremely flexible hierarchical/decision-making structures.

\section{Hypothesis}

In summary, the prescriptions put forth by the IFAC (2009) point to enlarging the action repertoire of governance routines and procedures to produce effective outcomes, or failure avoidance. The HRO literature supports the idea that adding specific actions would enable people to discover errors and threats in a mindful manner. As Weick et al. (1999, p. 90) observe “... the richness of a state of mindfulness is determined by the richness of the action repertoire. The richness of that action repertoire, in turn, is determined partly by the extent to which cognitive processes are stable and continue to develop and partly by the extent to which the repertoire of variable routines that uncover and manage unexpected events continues to expand". Building on this argument and theoretical support, the capacity for mindfulness should be enhanced through expanding levels of governance denominated by conformance and performance routines. Specifically, the following research hypothesis is tested:

H1: Increasing governance, depicted by higher levels of conformance and performance routines, positively influences the capacity for mindfulness.

\section{The Effects of MAS Change}

The literature overarching change in management accounting systems is quite diverse. A number of theoretical perspectives have been utilized, ranging from information system theory (Cooper and Zmud, 1990), theories of innovation and diffusion (Malmi, 1999), and institutional theory (Burns and Scapens, 2000) to organizational politics (Burns and Vaivio, 2001), trust (Tomkins, 2001), and epistemological issues (Quattrone and Hopper, 2001). In most instances, this literature has tried to supply organizational circumstances or structures, various motives, or effects that are linked directly or indirectly to the phenomenon of change in management accounting systems. Empirical research on MAS change has been equally varied. Some studies have focused on the implementation or success of specific techniques or sub-systems, such as activity-based costing (Innes and Mitchell, 1990; Shields, 1995), life-cycle costing (Shields and Young, 1991), balanced scorecard (Kaplan and Norton, 1992), and target costing (Dutton and Ferguson, 1996). In other work, Sulaiman and Mitchell (2005) cite substantial research involving a singular perspective on management accounting system increases, reductions, modifications, or replacements, and then offer a consolidated empirical analysis. 
Still other research examines change in management accounting systems utilizing a contingency perspective (Libby and Waterhouse, 1996; Laitinen, 2001; Williams and Seaman, 2001, 2002; Seaman and Williams, 2006). For example, Libby and Waterhouse (1996) used structural variables to predict MAS change, including five sub-systems, for a sample of Canadian manufacturing firms while Williams and Seaman (2001) replicated and extended their work in the Singapore context. Laitinen (2001) analyzed four classes of MAS change across 12 contextual and organizational variables for a sample of Finnish technology firms. Finally, only two studies treat MAS change (or sub-systems) as an independent variable. Williams and Seaman (2002) deploy a path analytic framework to examine the effects of MAS change on performance, not directly, but indirectly through supplying managerial relevant information under the moderating conditions of high task difficulty and high task variability. Seaman and Williams (2006), meanwhile, focus on the interaction effects of sub-systems change on performance and the moderating effects of perceived environmental uncertainty on this linkage.

What this literature illuminates collectively is that MAS change pervades organizational activity, both in frequency and importance, but this must be accomplished in an institutionalized way as Sulaiman and Mitchell (2005, p. 424) point out in citing Scapens (1994) and Burns and Scapens (2000): “... it has to fit the rules, routines and common ways of thinking and doing which exist within every organization ...”. For accountants in particular, MAS change potentially expands the action repertoire and enhances processes of understanding, evidence collection, detection, evaluation, and revising in the sense defined by Weick et al. (1999). Thus, one would expect that MAS change, in general, would augment the governance routines underlying conformance and performance as well as enriching the capability for mindfulness. By this line of reasoning, high levels of MAS change in a governance setting should provide a stronger link between the conformance/performance dimensions and the capacity for mindfulness relative to low levels of MAS change. Therefore, the second hypothesis tested is:

H2: When MAS change is high, there is a significantly stronger relationship between capacity for mindfulness and governance than when MAS change is low.

\section{RESEARCH DESIGN AND METHOD}

\section{Sample}

In 2005, registered members of the Society of Management Accountants of Canada were invited to respond via e-mail to a comprehensive questionnaire containing eleven separate survey instruments involving matters of governance, performance, uncertainty, behaviour, and accounting system changes, in addition to demographic data. The electronic details were appended to an article appearing in the CMA Magazine, which has a large Canadian audience of CFOs and controllers. Prior to the invitation, the complete research instrument was pilot-tested on nine small- to medium-sized firms and feedback indicated the task was time consuming and only serious respondents would fully complete the survey. These executives were targeted because of their superior professional expertise, firm-wide knowledge of accounting and information systems, and interactive role in governance issues.

To be admissible for analysis, e-mail responses were subjected to several filters. First, incomplete questionnaires were removed as well as those showing no variance across individual items. Second, respondents were cross-referenced for active membership and designation to the Society's registry. Third, respondents were required to have a CFO or equivalent position and accountability roles for governance matters in the organization. Finally, respondents were required to have been in their designated position for a minimum of four years.

Initially, 347 responses were received within a two-month period of invitation while 563 were received in total after four months. Applying the filters outlined yielded a final usable sample of 138 firms. Procedures for response and non-response bias normally applicable to mailed questionnaires were not possible. However, comparative cross-sectional correlations partitioned on early/late responses for all relevant research variables showed no significant abnormalities. Respondents had been employed by their respective organizations for an average of 11.2 years and had held their designated positions for 6.2 years on average. Finally, firms varied in size from small (100 to 300 employees) to large (greater than 1000 employees) and spanned the manufacturing (82 percent) and service (18 percent) sectors of the Canadian economy. 


\section{Measures}

\section{Governance}

Six scales to measure the performance and conformance dimensions of governance were adapted from guidelines published by the Governance Institute of Canada. The objective of the three performance scales (Appendix A) was to capture the accountant's role in the core processes of oversight of strategy implementation and evaluation, value creation, and the alignment of business operations and resource utilization outlined by the IFAC (2009). The variable "strategy" (P1) was constructed from a three-item scale, which yielded a single factor with an eigenvalue of 2.56 that explained 85 percent of the total variance. The variable "communication" (P2) was developed from a three-item scale that produced one factor with an eigenvalue of 2.20 , accounting for 74 percent of the total variation. In the context of work routines underpinning the CFO's job, the alignment of business operations and resources utilization is largely accomplished by effective communication among important stakeholders and a three-item scale was employed to reflect this quality and to create the variable "value creation" (P3). A factor analysis revealed one factor with an eigenvalue of 2.13 , explaining 71 percent of the total variance.

Three scales were also developed to capture the conformance dimension of governance in the spirit put forth by the IFAC (2009), namely, accountability in the reporting function, assurances of ethical conduct and managing conflicts of interest, and the effectiveness of risk oversight. A three-item scale was constructed to create the variable "accountability" $(\mathrm{C} 1)$ while two-item scales were used to create the variables "assurance" $(\mathrm{C} 2)$ and "risk" (C3). Factor analysis of each scale yielded single factors, with eigenvalues of 2.16, 1.91, and 1.86 that explained 72 percent, 95 percent, and 92 percent of the total variation, respectively.

Items for all six scales were rated on a fully anchored Likert scale ranging from 1 (to a very little extent) to 5 (to a very great extent) and an average score was calculated for each scale. The emergence of eigenvalues greater than unity confirmed the single-factor structure of each scale. Finally, reliability coefficients for each scale were calculated using Cronbach's (1951) alpha statistic, yielding 0.91, 0.81, 0.79, 0.80, 0.95, and 0.92 for P1, P2, P3, C1, C2, and C3, respectively. These coefficients are very strong and well within Nunnally's (1967) inter-item reliability standard for exploratory research.

\section{Mindfulness}

Based on the work of Weick and Sutcliffe (2001), five scales were adapted for use in this study to capture a composite measure of capacity for mindfulness. A four-item scale was used to measure "preoccupation with failure" and a factor analysis revealed only one factor with an eigenvalue of 2.16, which explained 61 percent of the total variance. For "reluctance to simplify", a three-item scale was employed and a factor analysis produced a single factor with an eigenvlaue of 2.20, explaining 73 percent of the total variation. A four-item scale was also used to measure "sensitivity to operations". Factor analysis yielded one factor with an eigenvalue of 2.68 , which accounted for 67 percent of the total variation. Finally, a four-item and three- item scale were used to measure "commitment to resilience" and "deference to expertise", respectively. Factor analysis revealed only a single factor for each scale with eigenvalues of 2.07 and 2.02 that explained 63 percent and 68 percent of the total variance, respectively.

All items across the five constructs were anchored by a five-point Likert scale ranging from 1 (to a very little extent) to 5 (to a very great extent). The factor analysis results confirmed the single-factor structure of each scale. The computed reliability coefficients for each scale were remarkably strong, ranging from 0.67 to 0.83 , and again well within accepted limits for exploratory research. For subsequent analysis, an average score was first computed for each scale. Next, the average scores from each scale were summed up and an overall average score was calculated to construct a composite capacity for mindfulness variable, CMIND. The Cronbach reliability coefficient computed for this overall measure was 0.88 .

\section{MAS Change}

A five-part scale initially developed by Libby and Waterhouse (1996) and subsequently used by Williams and Seaman (2001) and Seaman and Williams (2006) was used to develop a measure of MAS change. For each 
firm, data was collected on system changes to planning, controlling, costing, directing, and decision making (see Appendix C). Each respondent was asked to identify changes in these five categories for a period of three years prior to receiving the invitation to participate in the present study ${ }^{2}$. The time period restriction is consistent with previous research using this scale and acknowledges the need to compromise on potential hindsight bias arising from an extended time period.

To facilitate testing of hypothesis $\mathrm{H} 2$, a median split was performed on the total sample. All scores of the MAS change variable falling within plus or minus five percent of the median score were eliminated to produce two sub-samples, namely, low MAS change and high MAS change. A t-test confirmed that the two sub-samples are significantly different statistically $(\mathrm{t}=40.523 ; \mathrm{p}<0.000)$ while control checks for organization size $(\mathrm{t}=1.401 ; \mathrm{p}=$ 0.159 ) showed no significant difference.

\section{Analysis}

To investigate the effects of corporate governance processes on the capacity for mindfulness, hypothesis $\mathrm{H} 1$, a multiple regression model of the following form was used:

$\mathrm{CMIND}=\alpha+\beta_{1} \mathrm{P} 1+\beta_{2} \mathrm{P} 2+\beta_{3} \mathrm{P} 3+\beta_{4} \mathrm{C} 1+\beta_{5} \mathrm{C} 2+\beta_{6} \mathrm{C} 3+\epsilon$

where CMIND = capacity for mindfulness, $\mathrm{P} 1=$ strategy, $\mathrm{P} 2=$ value creation, $\mathrm{P} 3=$ communication, $\mathrm{C} 1=$ accountability, $\mathrm{C} 2=$ assurance, and $\mathrm{C} 3=$ risk. An insignificant finding would provide evidence of no main effects of the performance and conformance dimensions of governance on capacity for mindfulness and, hence, rejection of hypothesis H1. To test hypothesis H2, Eq. (1) was re-run for both the low and high MAS change sub-samples. A significantly higher $\mathrm{R}^{2}$ for the high MACS sub-sample relative to the low MACS sub-sample would provide support for hypothesis $\mathrm{H} 2$.

\section{RESULTS}

\section{Descriptive Statistics}

Table I displays the means, standard deviations, theoretical, and actual ranges for all variables in the study. Although not shown, a profile of the number of MAS changes as a percentage of the total changes for each of the five sub-categories was highly consistent with that reported by Libby and Waterhouse (1996), Williams and Seaman (2001), and Seaman and Williams (2006) in using the identical instrument ${ }^{3}$.

Table I: Descriptive Statistics $(n=124)$

\begin{tabular}{lcccc}
\hline Variable & Mean & $\begin{array}{c}\text { Standard } \\
\text { Deviation }\end{array}$ & $\begin{array}{c}\text { Theoretical } \\
\text { Range }\end{array}$ & $\begin{array}{c}\text { Actual } \\
\text { Range }\end{array}$ \\
\hline 1. CMIND & 3.422 & 0.620 & $1-5$ & $1-5$ \\
2. Strategy (P1) & 3.591 & 1.163 & $1-5$ & $1-5$ \\
3. Communication (P2) & 2.723 & 1.215 & $1-5$ & $1-5$ \\
4. Value creation (P3) & 3.643 & 0.986 & $1-5$ & $1-5$ \\
5. Accountability (C1) & 4.240 & 0.902 & $1-5$ & $1-5$ \\
6. Assurance (C2) & 2.934 & 1.386 & $1-5$ & $1-5$ \\
7. Risk (C3) & 3.230 & 1.309 & n/a & $1-5$ \\
8. MASC & 25.211 & 28.748 & & $0-132$ \\
\hline Vas & & &
\end{tabular}

Variable definitions:

CMIND = capacity for mindfulness

MASC $=$ management accounting systems change

The Pearson correlation matrix for the measured variables is given in Table $\mathrm{II}^{4}$. As expected, there are statistically significant positive correlations among the independent governance variables. Since corporate governance is a complex general construct, it is not surprising that there is modest correlation among the 
independent variables ${ }^{5}$. Also, MASC is not significantly correlated with the dependent variable or any of the independent variables. Viewing MASC as a moderating variable, these findings satisfy an important property of no correlation as argued by Shields and Shields (1998).

Table II: Pearson Correlation Matrix $(\mathrm{n}=124)$

\begin{tabular}{llllllll}
\hline Variable & $\mathbf{1}$ & $\mathbf{2}$ & $\mathbf{3}$ & $\mathbf{4}$ & $\mathbf{5}$ & $\mathbf{6}$ & $\mathbf{7}$ \\
\hline 1. CMIND & & & & & & \\
2. Strategy (P1) & $0.469^{* *}$ & & & & & \\
3. Communication (P2) & $0.644^{* *}$ & $0.350^{*}$ & & & & \\
4. Value creation (P3) & $0.439^{* *}$ & $0.471^{* *}$ & $0.352^{*}$ & & & \\
5. Accountability (C1) & $0.292^{*}$ & $0.438^{* *}$ & $0.372^{*}$ & $0.337^{*}$ & & & \\
6. Assurance (C2) & $0.514^{* *}$ & $0.424^{* *}$ & $0.544^{* *}$ & $0.484^{* *}$ & $0.406^{* *}$ & & \\
7. Risk (C3) & $0.390^{*}$ & $0.490^{* *}$ & $0.587^{* *}$ & $0.387^{*}$ & $0.537^{* *}$ & $0.592^{* *}$ & \\
8. MASC & 0.043 & $(0.010)$ & $(0.062)$ & 0.023 & 0.038 & 0.039 & $(0.050)$ \\
\hline
\end{tabular}

Variable definitions:

CMIND = capacity for mindfulness

MASC $=$ management accounting system changes .

$*<0.05$

$* *<0.01$

\section{Regression Results}

Results of the regression analysis are summarized in Table III. Hypothesis $\mathrm{H} 1$ posits that the independent governance variables will have a positive effect on the capacity for mindfulness. The results of Eq. (1) shown in column 1 indicate a significant relationship (adjusted $\mathrm{R}^{2}=0.478 ; \mathrm{F}=19.382 ; \mathrm{p}<0.011$ ) and thus provide support for hypothesis $\mathrm{H}^{5}$. For the performance dimension of governance, variables P2 and P3 are statistically significant positively at conventional levels while P1 does not have a significant relationship with mindfulness. Turning to the conformance dimension, only variable $\mathrm{C} 2$ has a significant positive impact on mindfulness. Variables $\mathrm{C} 1$ and $\mathrm{C} 3$ have opposite signs (marginally) to what was predicted but both are statistically insignificant. Nonetheless, these regression findings together with the correlation results provide strong support for Hypothesis H1.

Table III: Regression Results

\begin{tabular}{llcc}
\hline Variable & Full Model & Low MASC & High MASC \\
\hline Strategy (P1) & 0.041 & 0.154 & $(0.276)^{*}$ \\
Communication (P2) & $0.167^{*}$ & 0.008 & $0.348^{* *}$ \\
Value creation (P3) & $0.494^{* * *}$ & $0.385^{* *}$ & $0.641^{* * *}$ \\
Accountability (C1) & $(0.011)$ & 0.101 & $(0.050)$ \\
Assurance (C2) & $0.198^{* *}$ & $0.293^{*}$ & 0.162 \\
Risk (C3) & $(0.021)$ & $(0.223)$ & 0.107 \\
N & 124 & 51 & 53 \\
$\mathrm{R}^{2}$ & 0.496 & 0.468 & 0.683 \\
Adjusted $\mathrm{R}^{2}$ & 0.478 & 0.403 & 0.636 \\
F & $19.382^{* * *}$ & $6.452^{* * *}$ & $15.924 * * *$ \\
\hline
\end{tabular}

Variable definitions:

MASC $=$ management accounting system changes .

$*<0.10$

$* *<0.05$

$* * *<0.01$

Hypothesis $\mathrm{H} 2$ posits that the relationship between the governance variables and mindfulness will be stronger under high levels of MASC as opposed to low levels of MASC. Accordingly, Eq. (1) was re-estimated for each of the two sub-samples and the results appear in columns 2 and 3 of Table III ${ }^{7}$. A significant relationship between the governance variables and mindfulness emerges when the level of MACS is low (adjusted $\mathrm{R}^{2}=0.472 ; \mathrm{F}$ 
$=6.452 ; \mathrm{p}<0.010$ ). However, an even stronger relationship occurs when the level of MACS is high (adjusted $\mathrm{R}^{2}=$ $0.637 ; \mathrm{F}=15.927 ; \mathrm{p}<0.010)^{6}$. To provide a direct test of hypothesis $\mathrm{H} 2$, the regression results from columns 2 and 3 were compared using the Chow test (Chow, 1960) to test for structural differences. The result revealed that the two regression equations were significantly different $(F=6.117 ; \mathrm{p}<0.010)$. This result confirms the expected moderating effect of MASC on the governance-mindfulness relationship and provides strong support for hypothesis $\mathrm{H} 2$.

For low MASC, positive increases in variables P3 and C2 influence mindfulness the most. Surprisingly, the coefficient for $\mathrm{C} 3$ is significantly negative implying that mindfulness is positively influenced only through decreases in risk. Turning to high MASC, none of the governance variables relating to conformance significantly influence mindfulness. However, all variables reflecting the performance dimension of governance are significantly associated with mindfulness, with P1 having a negative influence and both $\mathrm{P} 2$ and $\mathrm{P} 3$ a positive influence. There is compelling evidence that even though the most dominant variables emerging under low and high MASC are different, each set of governance variables enhances mindfulness accordingly as reflected in the $\mathrm{R}^{2}$ values reported in Table III.

\section{Additional Analysis}

The results presented above are based on an analysis of direct main effects of variables representing the two governance dimensions on capacity for mindfulness. However, the IFAC (2009, p. 9) states that "performance and conformance dimensions enhance each other and the organization as a whole ...." The implication here is that the analysis underpinning the model specified in Eq. (1) is incomplete since no interaction effects were considered. To rectify this concern, an expanded regression model containing all the cross-products of variables P1 and C1, in addition to the original variables, was estimated for the full sample and each MASC sub-sample. Results (not shown) indicated no significant $\mathrm{R}^{2}$ changes and, moreover, none of the coefficients for the interaction variables were statistically significant. These findings suggest that the impact of the performance and conformance dimensions on the capacity for mindfulness are driven by main effects only and not interaction effects, at least for the sample used in this study.

A second concern relates to the appropriateness of measuring MAS change in absolute magnitude as originally presented by Libby and Waterhouse (1996). They measured MAS change as the number of reported system changes out of 23 sub-systems and decomposed this set in absolute magnitudes according to the five categories listed in Appendix A. Seaman and Williams (2006) reference literature which suggests that the effects of accounting systems change might be anchored to the number of existing systems at the time of change in terms of enhanced perceptions (Hopwood, 1987), experience, or the capacity to assimilate change (Levitt and March, 1988; Cohn and Leventhal, 1990; Libby and Waterhouse, 1996).

To accommodate this concern, a different measure of the MAS change variable was constructed by developing a ratio incorporating the number of absolute changes over the number of sub-systems in use for each of the five categories in Appendix A. For each firm, an index of MAS change was calculated. The total sample was again split at the median (reduced by plus and minus five percent) to create low and high categories of MAS change based on the index scores and the previous regressions were re-estimated. No statistically significant findings were revealed, suggesting that an index of MAS change does not moderate the relationship between the governance variables and capacity for mindfulness for the present sample of firms.

\section{DISCUSSION AND IMPLICATIONS}

The objective of this study was to explore the relationship between the two dimensions of conformance and performance identified by the IFAC (2009) and the notion of capacity for mindfulness developed in the organizational literature for HROs. Amidst the backdrop of increasing corporate failures, the IFAC's effort to evaluate and upgrade corporate governance through improved processes and practices is noteworthy. However, this recipe assumes that increased governance routines operate directly on "better outcomes" and "continuing effectiveness of [their] governance systems" (IFAC, 209, p.5). The HRO literature suggests that this linkage is not direct; instead, cognitive processes underpin the concept of mindfulness, which in turn, improve one's capability to 
manage both expected and unexpected events, thus improving effectiveness through increased reliability (Weick et al., 1999, p. 89).

The results underlying hypothesis $\mathrm{H} 1$ indicate a strong overall relationship between the governance variables and the cognitive effects of capacity for mindfulness, supported by the significant correlations reported in Table II and the adjusted $\mathrm{R}^{2}$ of $0.478(\mathrm{~F}=19.382 ; \mathrm{p}<0.001)$ reported in Table III. The regression analysis for the full sample shows that, within the conformance dimension, the assurance variable (C2) is the most significant determinant of capacity for mindfulness while the risk (C3) and accountability (C1) variables are not significant determinants of capacity for mindfulness.

These outcomes suggest that the repertoire of routines overarching the risk and accountability functions of corporate governance expand at significantly lower rates than those associated with assurance. Indeed, practicing accountants at senior levels of the organization are probably involved with issues of risk, albeit indirectly rather than directly, thus limiting their ability to enlarge the network of risk processes and procedures. The same reasoning applies to accountability which does not emerge as a significant determinant of mindfulness, since even top-level accountants are constrained by institutionalized categories of financial reporting and the boundaries of generally accepted accounting principles which prevent enlargement of the action repertoire. Alternatively, it is possible that the risk and accountability variables used in this study were not measured with sufficient discriminatory detail to produce the anticipated effect on capacity for mindfulness.

Turning to the performance dimension of governance, both the communication (P2) and value creation (P3) variables are significant determinants of capacity for mindfulness, with the latter being the most important. However, the regression analysis shows that strategy (P1) is not a significant determinant of capacity for mindfulness. These performance dimension outcomes, generally, are not consistent with concerns advanced in a report by the IFAC (2008) indicating that organizations direct a disproportionate amount of attention to compliance and their governing bodies do not focus enough on matters subsumed under performance and building a business. Nonetheless, the non-significance of strategy on the capacity for mindfulness is curious. It may be that top-level accountants encounter a paradox in the sense offered by Roberts and Creed (1993) in that they are asked to design information systems that communicate efficiently, which encourages integration and simplification. Yet, to reduce mis-specification in strategy and direction, "structural and cognitive mechanisms that encourage the sensing and organization of detail" are required (Weick et al., 1999, p.108). This requirement demands different systems, ones that are more complex and less consolidated. For the present sample, the enlargement of routines to handle strategy in a complex un-integrated manner by top-level accountants appears to be missing and, therefore, no significant influence on capacity for mindfulness is observed.

The significant relationship between the governance variables and capacity for mindfulness persists across both low and high levels of MASC, supported by the respective adjusted $R^{2}$ of $0.403(F=6.452 ; p<0.001)$ and $R^{2}$ of $0.636(\mathrm{~F}=15.924 ; \mathrm{p}<0.001)$ as reported in Table III. Hypothesis $\mathrm{H} 2$ posits a significantly stronger relationship under the condition of high MASC versus low MASC and the Chow test F-statistic testing for structural change between the two regressions supports $\mathrm{H} 2$. Thus, the significant incremental explanatory power of 23.3 in $\mathrm{R}^{2}$ for high MASC over low MASC provides strong statistical support for $\mathrm{H} 2$.

However, Table III shows that the pattern of important governance variables influencing capacity for mindfulness under each level of MASC is fundamentally different. When MASC is low, assurance (C2) emerges as the only significant determinant of CMIND from among the three compliance variables whereas only value creation (P3) from among the three performance variables is a significant predictor of capacity for mindfulness, CMIND. Thus, in an environment of low MASC both dimensions of governance are important in influencing capacity for mindfulness, which is consistent with 'getting the balance right' for avoiding failure and ensuring success - a position advocated by the IFAC and Chartered Institute of Management Accountants (2004). More research is required, however, to understand why variables $\mathrm{C} 2$ and $\mathrm{P} 3$ are the only significant predictors of capacity for mindfulness when MASC is low. Other organizational variables, such as perceived environmental uncertainty (Seaman and Williams, 2006), intensity of competition, or decentralization (Libby and Waterhouse, 1996) could play a moderating role, especially with respect to compliance routines involving the management of risk and accountability and performance routines capturing processes of strategy. 
In a high MASC environment, the most important determinants of capacity for mindfulness are surprisingly different than for the low MASC environment. None of the variables associated with the compliance dimension of governance are significant predictors. For the performance dimension variables, variables P2 and P3 are significantly positive determinants of capacity for mindfulness but strategy (P1) is unexpectedly a significantly negative predictor. These findings suggest, first, that there are possibly strict limits to the enlargement of compliance routines and that there is more scope for developing the performance dimension of governance. Given an environment where MAS change is higher provides for some of this expansion, which has a positive influence on capacity for mindfulness. Second, the significant positive effects of communication (P2) and value creation (P3) on capacity for mindfulness are in accord with the generally recognized hallmark qualities of professional accountants in designing robust management accounting systems.

Finally, it is difficult to rationalize the significantly negative effect of the strategy variable, $\mathrm{P} 1$, on mindfulness when MASC is high. Perhaps the variable routines associated with strategic action are not compatible with new management accounting systems and create more uncertainty for professional accountants in practice, thus interfering with capacity for mindfulness. More experience, familiarity, or learning may dampen this negative effect over time. At the other extreme, it is possible that the sub-sample of high MASC included responses that are more aligned with success than failure. For example, previously used strategic planning systems may have been modified and identified as changes when in fact they were simply extensions of old models that were successful. In quoting from Millar (1993), Weick et al. (1999, p. 90) claim that "this preoccupation tends to encourage simplification and exploitation of existing performance routines, adherence to institutionalized categories, and compliance with inherited job descriptions all of which represent acts that are largely mindless".

In summary, this exploratory study uses descriptions of the conformance and performance dimensions of governance (IFAC, 2009) as determinants of capacity for mindfulness, a cognitive dimension developed in the organizational literature on HROs. Results from the full sample show significant explanatory power in the governance variables with respect to capacity for mindfulness in the context of high-level accounting professionals, and this explanatory power persists under conditions of low MACS. For high MACS, the explanatory power of the governance measures on capacity for mindfulness is significantly higher, but the emphasis comes from the performance dimension of governance and not the conformance dimension. These findings have implications for the types of governance dimensions supported by changes in management accounting systems that influence capacity for mindfulness and, subsequently, in enhancing organizational effectiveness through these cognitive processes.

In closing, this study is subject to all the usual caveats directed at exploratory survey research, including hindsight bias associated with measuring the variable MASC (Libby and Waterhouse, 1996) and common-method bias from self-reported data (Kren, 1992). In addition to improved measures for the independent and dependent variables, future research might consider the effects of MASC on the governance/mindfulness relationship through other organizational contingency factors such as environmental uncertainty (Khandwalla, 1972), task uncertainty, and decentralization (Drazin and Van de Ven, 1985; Gresov, Drazin and Van de Ven, 1989). It may be insightful as well to decompose the dimensions of governance analytically and compare the separate effects of compliance and performance on capacity for mindfulness. Clearly, a larger sample would be instructive in all these potential endeavours.

\section{ENDNOTES}

1. The expression "MAS change" refers to the set of five management accounting system components originally developed by Libby and Waterhouse (1996). The abbreviation "MASC" represents the moderating variable used in the regression models.

2. Respondents were directed to identify MAS changes for only the fiscal years 2002, 2003 and 2004, generating a total of 36 months. The Libby and Waterhouse study covered the years 1991-1993, a total of 36 months. Williams and Seaman reported MAS changes over a period of 30 months. Hence, the time line is consistent with previous research and attempts to minimize the confounding problem of hindsight bias. 
3. A direct comparison of total MAS changes in the present study to Libby and Waterhouse (1996) or Williams and Seaman (2001) is confounded by several factors: (1) the sample size is much larger in the present study; (2) the industry composition is more diverse in the present study; and (3) the latter studies were confined to smaller and medium-sized firms which is not the case in the present study.

4. The Kolmogorov-Smirnov test for univariate normality was applied to both the dependent and independent variables and the z-statistics were not significant. The null hypothesis that the sample was drawn from a normal population could not be rejected at a significance level of $\mathrm{p}<0.10$.

5. Although statistically significant, the magnitudes of the correlation coefficients among the independent variables are not large. Most likely the weak correlations occurred because the independent variables are sub-dimensions of a larger single construct representing firm governance. This phenomenon is not unusual in the behavioural literature (see for example Perrow, 1970; Brownell, 1982; Daft, 1983).

6. The full regression model in column 1 could be sensitive to multicollinearity and, thus, a Variance Inflation Factor was calculated. The result was well within acceptable limits, with the VIF slightly above 1.

7. Separate correlations, as reported in Table II, were recalculated for each sub-sample and no significant differences were discovered. Moreover, all variables in each sub-sample were tested for univariate normality using the Kolmogorov-Smirnov $z$-statistic and the Mahalanobas multivariate test was also applied to each regression. No abnormalities were found.

\section{REFERENCES}

1. Beasley, M. (1996), An empirical analysis of the relation between the board of director composition and financial statement fraud, The Accounting Review, Vol. 71, pp. 443-465.

2. Brownell, P. (1982), The role of accounting data in performance evaluation, budgetary participation, and organizational effectiveness, Journal of Accounting Research (Spring), pp. 12-27

3. Burns, J. and Scapens, R. (2000), Conceptualizing management accounting change: An institutional framework, Management Accounting Research, Vol. 11, pp. 3-25.

4. Burns, J. and Vaivio, J. (2001), Management accounting change, Management Accounting Research, Vol. 12, pp. 389-402.

5. Bushman, R. and Smith, A. (2001), Financial accounting information and corporate governance, Journal of Accounting and Economics, Vol. 32, pp. 237-334.

6. Chow, G. C. (1960), Tests on equality between set of coefficients in two linear equations, Econometrica, Vol. 28, pp. 591-605.

7. Cohn, W. M. and Levinthal, D. (1990), Absorptive capacity: A new perspective on learning and innovation, Administrative Science Quarterly, Vol. 35, pp. 128-152.

8. Cooper, R. and Zmud, R. W. (1990), Information technology implementation research: a technological diffusion approach, Management Science, Vol. 36, pp. 123-139.

9. Core, J., Guay, W. and Rusticus, T. (2006), Does weak governance cause weak stock returns? An examination of firm operating performance and analysts' expectations, Journal of Finance, Vol. 61, pp. 655-687.

10. Cronbach, L. J. (1951), Coefficient alpha and the internal structure of tests. Psychometrika, Vol. 16 (September), pp. 297-334.

11. Daft, R. L. (1983), Organizational theory and design, West Publishing, St. Paul, MN.

12. Drazin, R. and Van de Ven, A. H. (1985), Alternative forms of fit in contingency theory, Administrative Science Quarterly, Vol. 30, pp. 514-539.

13. Dechow, P., Sloan, R. and Sweeney, A. (1995), Detecting Earnings Management, The Accounting Review, Vol. 70, pp. 193-225.

14. Dechow, P., Sloan, R. and Sweeney, A. (1996), Causes and consequences of earnings manipulation: An analysis of firms subject to enforcement actions by the SEC, Contemporary Accounting Research, Vol. 13, pp. 1-36.

15. Dutton, J. J. and Ferguson, M. (1996), Target costing at Texas Instruments, Journal of Cost Management, Fall, pp. 33-38.

16. Erickson, M., Hanlon, M. and Maydew, E. (2006), Is there a link between executive compensation and accounting fraud?, Journal of Accounting Research, Vol. 44, pp. 113-143. 
17. Feldman, M. S. (1989), Order without design: Information production and policy making, Stanford University Press, Stanford, CA.

18. Galbraith, J. (1977), Organizational design, Addison-Wesley, Reading, MA.

19. Gompers, P., Ishii, J. and Metrick, A. (2003), Corporate governance and equity prices, Quarterly Journal of Economics, Vol. 118, pp. 107-155.

20. Gresov, C., Drazin, R. and Van de Ven, A. H. (1989), Work-unit task uncertainty, design and morale, Organization Studies, Vol. 10 No. 1, pp. 45-62.

21. Hannan, M. T. and Freeman, J. (1984), Structural inertia and organizational change, American Sociological Review, Vol. 49, pp. 149-164.

22. Hopwood, A. G. (1987), The archaeology of accounting systems, Accounting, Organizations and Society, Vol. 15, No.3, pp. 207-234.

23. Innes, J. and Mitchell, F. (1990), The process of change in management accounting: Some Field study evidence, Management Accounting Research, Vol. 1, pp.3-19.

24. International Federation of Accountants. (2009), International good practice guidance: evaluating and improving governance in organizations, New York.

25. International Federation of Accountants. (2008), Financial reporting supply chain: current perspectives and directions, New York.

26. IFAC and Chartered Institute of Management Accountants. (2004), Enterprise governance: Getting the balance right, New York.

27. Kaplan, R. S. and Norton, D. (1992), The balanced scorecard - measures that drive performance, Harvard Business Review, January/February, pp. 71-79.

28. Khandwalla, P. N. (1972), The effect of different types of competition on the use of management controls, Journal of Accounting Research, Vol. 10, pp.275-285.

29. Klein, A. (2002), Audit committee, board of director characteristics, and earnings management, Journal of Accounting and Economics, Vol. 36, pp. 375-400.

30. Kren, L. (1992), Budgetary participation and managerial performance: The impact of information and environmental volatility, The Accounting Review, Vol. 67, pp. 511-526.

31. Landau, M. and Chisholm, D. (1995), The arrogance of optimism: Notes on failure avoidance management, Journal of Contingencies and Crises Management, Vol. 3, pp. 67-80.

32. Langer, E. J. (1989), Minding matters: The consequences of mindlessness-mindfulness, in Berkowitz, L. (Ed.), Advances in experimental social psychology, Vol. 22, pp. 137-173, Academic Press, San Diego, CA.

33. Laitinen, E. K. (2001), Management accounting change in small technology companies: Towards a mathematical model of the technological firm, Management Accounting Research, Vol. 12, pp. 507-541.

34. Larcker, D. F., Richardson, S. A. and Tuna, I. (2007), Corporate Governance, Accounting Outcomes, and Organizational Performance, The Accounting Review, Vol. 84 No 4, pp. 963-1008.

35. Levitt, B. and March, J. G. (1988), Organizational learning, Annual Review of Sociology, Vol. 12, pp. 319340.

36. Libby, T. and Waterhouse, J. H. (1996), Predicting change in management accounting systems, Journal of Managerial Accounting Research, Vol. 8, pp. 137-150.

37. Malmi, T. (1997), Towards explaining acitivity-based costing failure: Accounting and control in a decentralized organization, Management Accounting Research, Vol. 20, pp. 459-480.

38. March, J. G. and Olsen, J. P. (1989), Rediscovering institutions, Free Press, New York.

39. March, J. G., Sproull, L. S. and Tamuz, M. (1991), Learning from samples of one or fewer, Organization Science, Vol. 2, pp. 1-13.

40. Miller, D. (1993), The architecture of simplicity, Academy of Management Review, Vol. 18, pp. 116-138.

41. Nunnally, J. C. (1967), Psychometric theory, McGraw Hill, New York.

42. Otley, D. (1999), Performance management: A framework for management control systems research, Management Accounting Research, Vol. 10 No. 4, pp. 363-382.

43. Perrin, C. (1995), Organizations as contexts: Implications for safety science and practice, Industrial and Environmental Crisis Quarterly, Vol. 4, pp. 152-174.

44. Perrow, C. (1970), Organizational analysis: A sociological review, Wadsworth Publishing, Belmont, CA.

45. Pricewaterhousecoopers. (2008), Todays Challenges, www.pwc.com.

46. Quattrone, P. and Hopper, T. (2001), What does organizational change mean? Speculations on a taken for granted category, Management Accounting Research, Vol. 12, pp. 403-435. 
47. Roberts, K. H. and Creed, W. E. D. (1993), Epilogue, in Roberts, K. H. (Ed.), New challenges to understanding organizations, (pp. 249-256), Macmillan, New York.

48. Roberts, K. H. and Rousseau, D. M. (1989), Research in nearly failure-free, high-reliability systems: Having the bubble, IEEE Transactions on Engineering Management, Vol. 36, pp. 132-139.

49. Roberts, K. H., Stout, S. K. and Halpern, J. J. (1994), Decision dynamics in two high reliability military organizations, Management Science, Vol. 40, pp. 614-624.

50. Rochlin, G. I. (1989), Informal organizational networking as a crisis avoidance strategy: U.S. naval flight operations as a case study, Industrial Crisis Quarterly, Vol. 3, pp. 11-32.

51. Rochlin, G. I. (1993), “Defining 'high reliability' organizations in practice: A taxonomy prologue, in Roberts, K. H. (Ed.), New challenges to understanding organizations (pp. 11-32), New York, Free Press.

52. Roth, G. (1979), Analysis of decision making in nuclear power plant emergencies: An investigation of aided decision making, in Zsambok, C. and Klein, G., (Eds.), Naturalistic decision making (pp. 175-182), Erlbaum, Mahwah, NJ.

53. Scapens, R. W. (1994), Never mind the gap: Towards an institutional perspective on management accounting practice, Management Accounting Research, Vol. 5, pp 301-321.

54. Seaman, A. E. and Williams, J. J. (2006), Management accounting systems change and sub-unit performance: The moderating effects of perceived environmental uncertainty, Journal of Applied Business Research, Vol. 22, pp. 103-117.

55. Shields, M. D. (1995), An empirical analysis of firms' implementation experiences with activity-based costing, Journal of Management Accounting Research, Vol. 7, pp. 148-166.

56. Shields, J. F. and Shields, M. D. (1998), Antecedents of participative budgeting, Accounting, Organizations and Society, Vol. 23, pp. 49-76.

57. Shields, M. D. and Young, S. M. (1991), Managing product life-cycle costs: An organizational model. Journal of Cost Management, Vol. 5, pp. 39-52.

58. Shleifer, A. And Vishny, R. (1997), A survey of corporate governance, Journal of Finance, Vol. 52 No. 2, pp. 737-783.

59. Sitkin, S. B. (1992), Learning through failure: The strategy of small losses, in Staw, B. M. and Cummings, L. L. (Eds.), Research in organizational behaviour (Vol. 14, pp. 231-266), JAI Press, Greenwich, CT.

60. Sulaiman, S. and Mitchell, F. (2005), Utilising a typology of management accounting change: An empirical analysis, Management Accounting Research, Vol. 16, pp. 422-437.

61. Tomkins, C. (2001), Interdependencies, trust, and information in relationships, alliances and networks, Accounting, Organizations and Society, Vol. 26, pp. 161-191.

62. Weick, K. E. (1979), The social psychology of organizing, Addison-Wesley, Reading, MA.

63. Weick, K. E. (1990), The vulnerable system: An analysis of the Tenerife air disaster, Journal of Management, Vol. 16, pp. 571-593.

64. Weick, K. E, and Sutcliffe, K. M. (2001), Managing the Unexpected. Jossey-Bass: San Francisco, CA.

65. Weick, K. E., Sutcliffe, K. M. and Obstfeld, D. (1999), Organizing for high reliability: Processes of collective mindfulness, Research in Organizational Behaviour, Vol. 21, pp. 81-123.

66. Wildavsky, A. (1991), Searching for safety, Transaction Books, New Brunswick.

67. Williams, J. J. and Seaman, A. E. (2001), Predicting change in management accounting systems: National culture and industry effects, Accounting, Organizations and Society, Vol. 26 No. 5, pp. 443-460.

68. Williams, J. J. and Seaman, A. E. (2002), Management accounting systems change and departmental performance: The influence of managerial information and task uncertainty, Management Accounting Research, Vol. 13, pp. 419-445.

69. Woods, D. D. (1988), Coping with complexity: The psychology of human behaviour in complex systems, in Goodstein, H. B. Andersen, H. B. and Olsen S. E. (Eds.), Task, errors, and mental models, pp. 128-148, Taylor and Francis, New York.

70. Xiao, Y., Milgram, P. and Doyle, J. D. (1997), Capturing and modeling planning expertise in anesthesiology: Results of a field study, in Zsambok, C. and Klein, G., (Eds.), Naturalistic decision making, (pp. 197-207), Mahwah, NJ, Erlbaum.

71. Xie, B, Davidson III, W. and Dadalt, P. (2003), Earnings management and corporate governance: the role of the board and audit committee, Journal of Corporate Finance, Vol. 9, pp. 295-316. 


\section{APPENDIX A: ABBREVIATED MINDFULLNESS QUESTIONNAIRE}

\section{Preoccupation with failure}

1. We make it hard for people to hide mistakes of any kind.

2. People are inclined to report mistakes that have significant consequences even if nobody notices.

3. Managers seek out and encourage bad news.

4. People are rewarded if they spot problems, mistakes, errors, or failures.

\section{Reluctance to simplify}

1. People in this organization feel free to discuss tough issues and problems.

2. People generally prolong their analysis to better grasp the nature of problems that come up.

3. People are encouraged to express different views of the world.

\section{Sensitivity to operations}

1. Supervisors readily contribute whenever necessary.

2. There is access to resources if unexpected outcomes arise.

3. On a day-to-day basis, there is an ongoing presence of someone who is paying attention to what is happening and is readily available for consultation if something unexpected arises.

4. Should problems occur, someone with the authority to act is always accessible and available, especially to people on the front lines.

\section{Commitment to resilience}

1. People around here are known for their ability to use their knowledge in novel ways.

2. People have a number of informal contacts that they sometimes use to solve problems.

3. Resources are continually committed to retraining people on features of the technical system.

4. This organization actively develops people's skills and knowledge.

\section{Deference to expertise}

1. When something out of the ordinary happens, people know who has the expertise to respond.

2. People in this organization value expertise and experience over hierarchical rank.

3. When people do not know how to handle a problem that arises, it is generally easy to obtain expert advice and assistance. 


\section{APPENDIX B: ABBREVIATED GOVERNANCE QUESTIONNAIRE}

\section{Strategy}

1. I interact and work with top management to develop corporate strategy.

2. I indentify and suggest criteria for measuring the organization's strategy.

3. I ensure that appropriate systems are in place to monitor the achievement of strategic objectives.

\section{Communication}

1. I ensure effective communication between the organization and its stakeholders.

2. I ensure effective communication between the organization and the general public.

3. I ensure effective communication is exchanged between the Board of Directors and operating personnel.

\section{Value Creation}

1. The organization has a continuous training program in place.

2. I am encouraged to learn and apply new knowledge within my organizational work role.

3. The organization encourages innovation and the development of new ideas.

\section{Accountability}

1. I ensure the integrity of data that is disseminated to various internal and external users.

2. I ensure compliance of the data with generally accepted accounting principles.

3. I review and approve financial data.

\section{Assurance}

1. I ensure that conflict of interest guidelines are adhered to by people in the organization.

2 I ensure that the code of ethical conduct is adhered to by people in the organization.

\section{Risk}

1. I identify the principle risks of the organization's business.

2. I ensure the implementation of appropriate risk management systems. 


\section{APPENDIX C: LIST OF MANAGEMENT ACCOUNTING SYSTEM COMPONENTS}

\section{Planning systems}

1. Budgeting

2. Operations planning (production)

3. Capital budgeting

4. Strategic planning

5. Other planning systems

\section{Controlling systems}

6. Individual or team-based performance measurement

7. Organizational performance measurement

8. Measurement of performance in terms of quality

9. Measurement of performance in terms of customer satisfaction

10. Other performance measures

Costing systems

11. Direct allocation of manufacturing overhead

12. Direct allocation of marketing costs

13. Direct allocation of other overhead

14. Internal (dept. or divisional) product transfers

15. Other costing systems

Directing systems

16. Reward systems - bonuses

17. Reward systems - pay-for-performance plans

18. Other reward systems

Decision making systems

19. Information reported more frequently

20. Use of more nonfinancial measures

21. Information reported more broadly

22. Other changes to reporting systems

23. Other changes to systems that do not appear on this list 
NOTES 